\title{
A rare cause of fever in an adult: a case of familial Mediterranean fever
}

This article was published in the following Dove Press journal: International Medical Case Reports Journal

\author{
Ilknur Erdem' \\ Fatih Saritas ${ }^{2}$ \\ Ritvan Karaali' \\ Enes Ardic' \\ Gaye Kubra Emeksiz \\ Sonat Pinar Kara ${ }^{3}$ \\ R Merve Yaniker ${ }^{4}$ \\ Oguzhan Bol ${ }^{4}$
}

'Department of Infectious Diseases, Faculty of Medicine, Namik Kemal University, Tekirdag, Turkey; ${ }^{2}$ Clinic of Rheumatology, Tekirdag State Hospital, Tekirdag, Turkey; ${ }^{3}$ Department of Internal Medicine, Faculty of Medicine, Namik Kemal University, Tekirdag, Turkey; ${ }^{4}$ Department of Emergency Medicine, Faculty of Medicine, Namik Kemal University, Tekirdag, Turkey
Correspondence: Ilknur Erdem Department of Infectious Diseases, Faculty of Medicine, Namik Kemal University, Tekirdag 59100, Turkey Tel +90532588 8235 Fax +902163106578 Email ilknurerdem@hotmail.com
Background: Familial Mediterranean fever (FMF) is a hereditary autoinflammatory disease characterized by recurrent fever attacks and serositis. Nonspecific manifestations of the FMF can mimic many common acquired disorders such as infections and acute abdomen. This can delay recognition for many years and lead to comprehensive assessments and even unnecessary surgeries. Untreated FMF may lead to serious complications such as end-stage renal disease and malabsorption due to amyloid deposits in the kidneys and the digestive system. Colchicine has been used successfully to treat FMF since the 1970s.

Case presentation: A 30-year-old male was admitted to our hospital with the complaints of fever, nausea, vomiting, and generalized myalgia and weakness for 15 days. The day after hospitalization, the patient had abdominal pain. Approximately a month before, the patient was treated for a diagnosis of urinary tract infection, with similar complaints. $M E F V$ gene mutation analysis revealed homozygosity for the R202Q mutation. FMF was considered in the patient due to the presence of recurrent febrile serositis attacks and R202Q homozygous mutation in the FMF gene analyses. Colchicine was started $3 \times 0.5 \mathrm{mg} /$ day by consulting rheumatology on day 8 of admission. After the colchicine treatment, the patient's complaints markedly improved and the inflammatory markers returned to normal levels. At his follow-up visit at 6 months, the patient remained asymptomatic.

Conclusion: We present a case of adult-onset FMF accompanied by peritonitis as a disease among the rare causes of fever in an adult who was treated with colchicine. Based on this case, we suggest that FMF should be kept in mind in the differential diagnosis of patients with periodic fever syndromes.

Keywords: familial Mediterranean fever, fever, peritonitis

\section{Introduction}

Familial Mediterranean fever (FMF) is an autosomal recessive genetic disorder characterized by recurrent attacks of fever with serosal inflammation, most commonly in people of Mediterranean origin. The first attack appears before the age of 20 in $>90 \%$ of the patients. Fevers are generally accompanied by symptoms of inflammation in one or more sites. These may include abdominal pain, chest pain, joint pain, and skin rashes, and other characteristic findings. Abdominal pain is the most frequent clinical complaint in FMF. The cause of abdominal pain is sterile peritonitis. These symptoms resemble acute abdomen during attacks. Abdominal attacks have been frequently misdiagnosed as acute appendicitis and unnecessary surgeries have been performed. Unnecessary laparotomy with the diagnosis of appendicitis is not rare. On the other hand, recurrent attacks of peritonitis may lead to abdominal or pelvic adhesions, with the potential 
for causing mechanical bowel obstruction, volvulus, and strangulation or infertility in female patients. A case of intestinal obstruction secondary to FMF peritonitis even under colchicine therapy has been reported. The diagnosis of FMF is based on the clinical criteria, family history, geographic and ethnic considerations, response to colchicine treatment, and genetic analysis of known mutations. Analysis of MEFV gene is the only method to be confirm the diagnosis of the disease. Colchicine is the gold standard and still the only recommended drug for treating FMF. ${ }^{1-5}$ Here, we present a case of adult-onset FMF accompanied by peritonitis as a disease among the rare causes of fever in an adult.

\section{Case presentation}

A 30-year-old male was admitted to our hospital with the complaints of fever, nausea, vomiting, and generalized myalgia, and weakness for 15 days. The day after hospitalization, the patient had abdominal pain. Approximately a month before, the patient was treated with a diagnosis of urinary tract infection with similar complaints. There was no family history of recurrent fevers. His physical examination showed a high temperature $\left(39.2^{\circ} \mathrm{C}\right)$ with widespread abdominal tenderness, and rebound and defense positivity. To rule out an acute abdomen due to appendicitis, abdominal ultrasonography and computed tomography were performed; radiological findings did not suggest appendicitis. Laboratory findings were as follows: hemoglobin: $11.2 \mathrm{~g} / \mathrm{dL}$, white blood cell count: $7500 / \mathrm{mm}^{3}$, C-reactive protein (CRP): $141 \mathrm{mg} / \mathrm{dL}$ (0-5 mg/ $\mathrm{dL}$ ), erythrocyte sedimentation rate (ESR): $88 \mathrm{~mm} / \mathrm{h}$, fibrinogen: $508 \mathrm{mg} / \mathrm{dL}(200-400 \mathrm{mg} / \mathrm{dL})$, d-dimer: $0.9 \mu \mathrm{g} / \mathrm{mL}$, serum amyloid A (SAA): $4205 \mathrm{mg} / \mathrm{L}$, serum creatinine $0.89 \mathrm{mg} / \mathrm{dL}$, serum albumin: $4.17 \mathrm{~g} / \mathrm{dL}$, serum Fe: $17 \mu \mathrm{g} / \mathrm{dL}$ (32-193), serum iron-binding capacity: $180 \mathrm{mg} / \mathrm{dL}$, and haptoglobulin: $498 \mathrm{mg} / \mathrm{dL}$. Antinuclear antibody, antineutrophil cytoplasmic antibody, rheumatoid factor, and Brucella agglutination tests were negative. There were 225 erythrocytes/hpf and 3 leukocytes/hpf on urine analysis; the $24 \mathrm{~h}$ urinary protein was $708 \mathrm{mg} / \mathrm{dL}$ and the $24 \mathrm{~h}$ urinary microalbumin was $291 \mathrm{mg}$ / dL. $M E F V$ gene mutation analysis revealed homozygosity for the R202Q mutation.

FMF was considered in the patient due to the presence of recurrent febrile serositis attacks and R202Q homozygous mutation in the FMF gene analyses. Colchicine was started $3 \times 0.5 \mathrm{mg} /$ day by consulting rheumatology on day 8 of admission. The patient's symptoms were successfully controlled by administration of colchicine. On the 7 th day of the treatment, the patient was discharged with colchicine treatment. After the colchicine treatment, there was a marked improvement in his complaints and the inflammatory markers returned to normal levels. At his follow-up visit at 6 months, the patient remained asymptomatic. The patient provided written informed consent to have the case details published.

\section{Discussion}

FMF is a disease that is characterized by recurrent fever and serosal inflammation (e.g., peritonitis, pleuritis, synovitis). The majority of affected individuals ( $80 \%$ ) present before 10 years of age and $90 \%$ present before reaching the age of 20 years. Onset of the disease at an older age may occur, but is rare after 40 years old. Acute episodes may last from 24 to $72 \mathrm{~h}$ and have variable frequencies. Some commonly reported precipitating causes include viral illness, emotional stress, excessive/intense physical activity, high-fat diet, extremes of temperature, and menstruation in women. The frequency of attacks may range from once a week to every 5-10 years, with the median frequency being approximately once a month. ${ }^{1,2,6,7}$ Our case was diagnosed at an advanced age because of the lack of typical presentation.

The majority of patients with FMF (95\%) experience abdominal pain, and this may be the first finding in half of the patients. It may remain localized or become widespread. The patient may present with a mild distension as well as a severe peritonitis. On physical examination, distension, rebound sensitivity, and decreased intestinal sounds are observed. Posterior peritoneum is rarely affected by FMF episodes and may be confounded with renal colic and acute pelvic inflammatory disease. As the abdominal episodes may be confounded with acute abdomen presentation in FMF, appendectomy and laparotomy may be needed. ${ }^{1,2,8}$ In our case, the patient had peritonitis and fever. Radiological findings did not suggest acute abdomen.

Acute episodes of FMF are associated with acute inflammation markers, such as CRP, fibrinogen, and SAA protein. However, elevated levels of SAA, CRP, and fibrinogen are nonspecific and do not critically contribute to the diagnosis. Molecular genetic diagnostic testing is used to provide a confirmation of the FMF diagnosis as it is obviously more specific than the other laboratory analytes such as ESR and CRP. Also, some researchers use SAA protein levels as an important marker of chronic inflammation in between attacks of FMF., ${ }^{2,-11}$ In our case, a marked increase in SAA suggested FMF.

The diagnosis still relies mainly on clinical criteria. Several diagnostic criteria have been shown in the literature. The most widely used criteria are the so-called Tel-Hashomer criteria, but actually refers to either Livneh et $\mathrm{al}^{12}$ or Sohar et $\mathrm{al}^{13}$ 
criteria. A favorable response to colchicine may be one of the most valuable criteria for diagnosing FMF. ${ }^{2}$ Clinically, our patient fulfilled the Tel-Hashomer diagnostic criteria (Sohar criteria) with two major criteria (recurrent febrile episode associated with peritonitis and favorable response to colchicine) and one minor criterion (recurrent febrile episodes).

Genetic analysis plays a certain role in the diagnosis of the disease. The gene responsible for FMF (MEFV) is localized on chromosome 16p13.3 and includes 10 exons. FMF exhibits an autosomal recessive pattern of inheritance, and patients are either homozygous or compound heterozygous for $M E F V$ mutations. Most of these mutations are in exon 10. The most commonly observed mutations ie, M694V, M680I, M694I, V726A, and E148Q, are responsible for a large percentage of mutations in different ethnic groups. The relationship between FMF and mutations such as M694V, M694I, M680I, V726A, and E148Q has been clearly established; however, the role of the amino acid substitution R202Q, where glutamine (Q) substitutes for arginine (R), has not been fully elucidated. However, in recent studies, a higher frequency of R202Q was found among patients with FMF compared to healthy controls, suggesting that R202Q may be a disease-causing mutation. ${ }^{12-16}$ In our case, genetic analysis demonstrated homozygous R202Q mutation.

Treatment of FMF is focused on the prevention of painful attacks and the development of amyloidosis. Nonsteroidal anti-inflammatory drugs may be used to treat individuals during acute episodes, although they are not always effective. Colchicine has been the mainstay of FMF treatment since 1972. It reduces the frequency, severity, and duration of attacks and prevents amyloidosis in almost all patients when used regularly on a lifelong basis at optimal doses. However, despite using maximum doses, 5\%-10\% of patients do not respond well to colchicine and $30 \%$ have partial response. These patients are either intolerant or resistant to colchicine. Interleukin-1 and tumor necrosis factor inhibitors may be effective in these settings. ${ }^{2,3,7}$ Our patient was diagnosed as FMF, and colchicine $1 \mathrm{mg}$ /day was prescribed to be taken lifelong. At his follow-up visit at 6 months, ESR, fibrinogen, and CRP values had returned to normal levels. Abdominal pain, fever, and arthritis had completely resolved.

\section{Conclusion}

We describe this case of adult-onset FMF accompanied by peritonitis as a disease among the rare causes of fever in an adult who was treated with colchicine. Based on this case, we propose that FMF should be kept in mind in the differential diagnosis of the patients with periodic fever syndromes.

\section{Author contributions}

All authors have contributed to the concept and design, acquisition of data, analysis and interpretation of data and revision of the manuscript. All authors gave final approval of the version to be published and agree to be responsible for all aspects of the work.

\section{Disclosure}

The authors report no conflicts of interest in this work.

\section{References}

1. Sohar E, Gafni J, Pras M, Heller H. Familial Mediterranean fever. A survey of 470 cases and review of the literature. Am J Med. 1967;43(2): $227-253$.

2. Sari I, Birlik M, Kasifoglu T. Familial Mediterranean fever: an updated review. Eur J Rheumatol. 2014;1(1):21-33.

3. Zemer D, Pras M, Sohar E, Modan M, Cabili S, Gafni J. Colchicine in the prevention and treatment of the amyloidosis of familial Mediterranean fever. N Engl J Med. 1986;314(16):1001-1005.

4. Kaya B, Eris C, Uctum Y. Delay in diagnosis of intestinal obstruction in a patient with familial Mediterranean fever. Clin Med Insights Case Rep. 2010:3 59-62.

5. Grateau G. Clinical and genetic aspects of the hereditary periodic fever syndromes. Rheumatology (Oxford). 2014;43(4):410-415.

6. Nobakht H, Zamani F, Ajdarkosh H, Mohamadzadeh Z, Fereshtehneiad SM, Nassaji M. Adult-onset familial Mediterranean fever in Northwestern Iran; clinical feature and treatment outcome. Middle East J Dig Dis. 2011;3(1):50-55.

7. Zadeh N, Getzug T, Grody WW. Diagnosis and management of familial Mediterranean fever: integrating medical genetics in a dedicated interdisciplinary clinic. Genet Med. 2011;13(3):263-269.

8. Kucuk A, Gezer IA, Ucar R, Karahan AY. Familial Mediterranean fever. Acta Medica (Hradec Králové). 2014;57(3):97-104.

9. Korkmaz C, Ozdogan H, Kasapcopur O, Yazici H. Acute phase response in familial Mediterranean fever. Ann Rheum Dis. 2002;61(1):79-81.

10. Ben-Zvi I, Livneh A. Chronic inflammation in FMF: markers, risk factors, outcomes and therapy. Nat Rev Rheumatol. 2011;7(2):105-112.

11. Duzova A, Bakkaloglu A, Besbas N, et al. Role of A-SAA in monitoring subclinical inflammation and in colchicine dosage in familial Mediterranean fever. Clin Exp Rheumatol. 2003;21(4):509-514.

12. Livneh A, Langevitz P, Zemer D, et al. Criteria for the diagnosis of familial Mediterranean fever. Arthritis Rheum. 1997;40(10): 1879-1885

13. Sohar E, Gafni G, Pras M. Tel Hashomer criteria for the diagnosis of FMF. In: E. Sohar, G. Gafni, M. Pras, editors. Proceedings of the First International Conference on FMF. London, UK: Freund Publishing House, Tel Aviv; 1997:207.

14. Lachmann HJ, Sengul B, Yavuzsen TU, et al. Clinical and subclinical inflammation in patients with familial Mediterranean fever and in heterozygous carriers of MEFV mutations. Rheumatology (Oxford). 2006;45(6):746-750.

15. Comak E, Akman S, Koyun M, et al. Clinical evaluation of R202Q alteration of MEFV genes in Turkish children. Clin Rheumatol. 2014;33(12):1765-1771.

16. Touitou I. The spectrum of familial Mediterranean fever (FMF) mutations. Eur J Hum Genet. 2001;9(7):473-483. 
International Medical Case Reports Journal

Dovepress

Publish your work in this journal

The International Medical Case Reports Journal is an international, peer-reviewed open-access journal publishing original case reports from all medical specialties. Previously unpublished medical posters are also accepted relating to any area of clinical or preclinical science. Submissions should not normally exceed 2,000 words or

4 published pages including figures, diagrams and references. The manuscript management system is completely online and includes a very quick and fair peer-review system, which is all easy to use. Visit $\mathrm{http}: / /$ www.dovepress.com/testimonials.php to read real quotes from published authors.

Submit your manuscript here: https://www.dovepress.com/international-medical-case-reports-journal-journal 